\title{
BMJ Open Lung function: population epidemiology and concordance in Australian children aged 11-12 years and their parents
}

\author{
Liam Welsh, ${ }^{1,2}$ Gayan Kathriachchige, ${ }^{3}$ Tahmeed Raheem, ${ }^{3}$ Anneke C Grobler, ${ }^{\oplus 1,3}$ \\ Melissa Wake, ${ }^{1,3,4}$ Sarath Ranganathan ${ }^{1,2,3}$
}

To cite: Welsh L,

Kathriachchige G, Raheem T, et al. Lung function: population epidemiology and concordance in Australian children aged $11-12$ years and their parents. BMJ Open 2019;9:53-62. doi:10.1136/ bmjopen-2018-023486

- Prepublication history for this paper is available online. To view these files, please visit the journal online (http://dx.doi. org/10.1136/bmjopen-2018023486).

Received 9 April 2018 Revised 7 June 2018 Accepted 4 April 2019

Check for updates

(C) Author(s) (or their employer(s)) 2019. Re-use permitted under CC BY-NC. No commercial re-use. See rights and permissions. Published by BMJ.

${ }^{1}$ Murdoch Children's Research Institute, Parkville, Victoria, Australia

${ }^{2}$ Respiratory Medicine, The Royal Children's Hospital,

Parkville, Victoria, Australia ${ }^{3}$ Department of Paediatrics, The University of Melbourne, Parkville, Victoria, Australia ${ }^{4}$ Department of Paediatrics and The Liggins Institute, The University of Auckland, Grafton, Auckland, New Zealand

Correspondence to Professor Melissa Wake; melissa.wake@mcri.edu.au

\section{ABSTRACT}

Objectives To describe the epidemiology of lung function in Australian children aged 11-12 years and their parents, and explore the degree of intergenerational concordance. Design Cross-sectional study (the Child Health CheckPoint) nested in the Longitudinal Study of Australian Children (LSAC).

Setting Assessment centres in seven Australian cities and eight regional towns, February 2015 to March 2016. Families unable to attend a clinic appointment were offered a home visit during the same period.

Participants 1874 families ( $53 \%$ of all eligible) participated in the study. Lung function data were available for 1759 children aged 11-12 years and 1774 parents (1668 biological pairs).

Outcome measures Participants completed spirometry with measures including forced expiratory volume in $1 \mathrm{~s}$ $\left(\mathrm{FEV}_{1}\right)$, forced vital capacity (FVC) and mid expiratory flow (MEF), converted to z-scores using Global Lung Initiative equations. Parent-child concordance was assessed using Pearson's correlation coefficients and multivariable linear regression models. Survey weights and methods accounted for LSAC's complex sampling, stratification and clustering within postcodes.

Results All lung function measures followed approximately normal distributions. Mean (SD) for $\mathrm{FEV}_{1}$ FVC and MEF z-scores in children were 0.33 (1.07), $0.83(1.14)$ and $-0.48(1.09)$, respectively. Mean (SD) in parents were 0.28 (1.10), 0.85 (1.15) and -0.45 (1.10), respectively. Parent FEV ${ }_{1}$, FVC and MEF were associated with child lung function with significant positive correlation coefficients $(0.22,95 \% \mathrm{Cl} 0.17$ to $0.26 ; 0.24,95 \% \mathrm{Cl} 0.20$ to 0.29 ; and $0.24,95 \% \mathrm{Cl} 0.20$ to 0.29 , respectively).

Conclusions Mean lung volumes were larger but with smaller airway size than international standards for both parents and children in this population sample. Modest associations between parent and child lung function highlight the potential for better identification of 'at risk' populations. Therefore, these findings may aid the development of health policy that aims to prevent the onset or limit the progression of lung disease.

\section{INTRODUCTION}

Non-communicable respiratory diseases such as chronic obstructive pulmonary
Strengths and limitations of this study

- Population-based sampling of Australian children provides a contemporary reference for future studies investigating lung function.

- This is the largest cross-sectional study to investigate lung function concordance in Australian parent-child dyads, thereby providing new insight into cross-generational patterns.

- Results were not adjusted for sitting height, which should be taken into consideration when interpreting the results.

- Most of the participating parents were mothers, resulting in less precise descriptive and concordance estimates for fathers.

disease (COPD), asthma, pulmonary fibrosis and lung cancer are the third leading cause of global mortality. ${ }^{1}{ }^{2}$ In Australia, mortality from chronic respiratory disease is currently 25.6 deaths per 100000 males and 15.5 deaths per 100000 females aged $<70$ years. ${ }^{3}$ In addition, these diseases can have extrapulmonary manifestations and therefore worsen the burden placed on healthcare resources. ${ }^{3}$ Without well-informed policy there is likely to be further demand on healthcare expenditure. ${ }^{4}$ The ability to identify those at highest risk of non-communicable respiratory disease could inform health policy that prevents the onset or limit the progression of lung disease.

Spirometry is a well-established clinical tool for assessing, diagnosing and monitoring respiratory disease in children and adults. It is a non-invasive method which allows to identify individuals with low or abnormal lung function, and compare both individuals and populations to international reference values. ${ }^{5}$ For example, a recent population study of spirometry data from 2066 Australian subjects aged $4-80$ years reported a mean difference of $<0.25$ for forced expiratory 


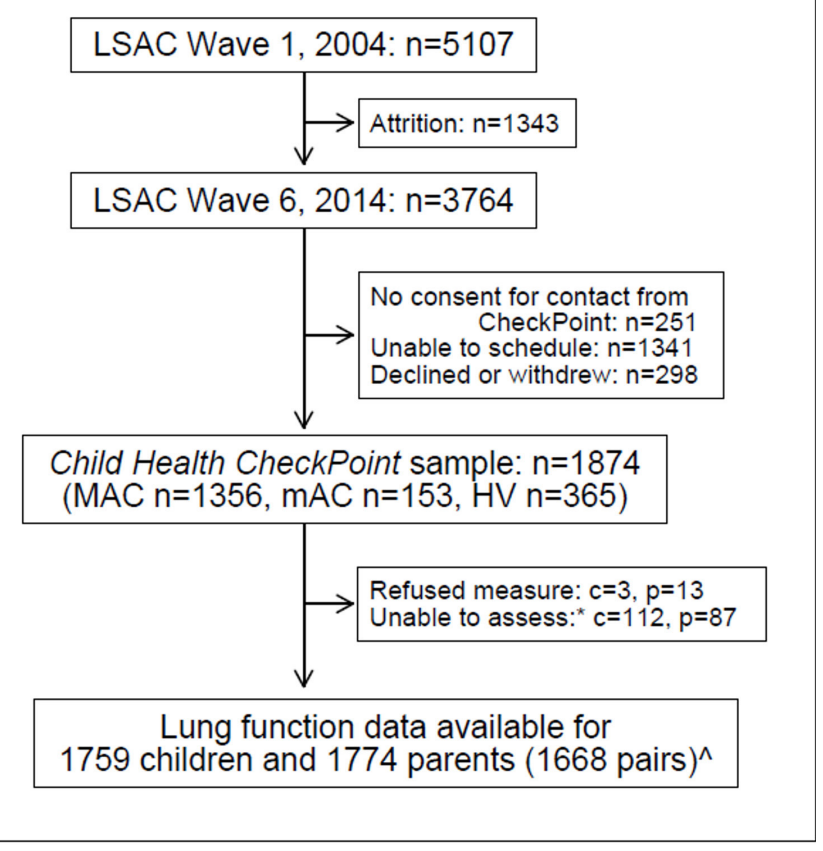

Figure 1 Participant diagram. n, number of families; $c$, number of children; $p$, number of attending adults; MAC, main assessment centre; $\mathrm{mAC}$, mini assessment centre; $\mathrm{HV}$, home visit assessment; LSAC, longitudinal study of Australian Children. *Unable to assess due to equipment failure, poor quality data or time contraints. ^Data from 20 non-biological child-parent pairs excluded from concordance analyses.

volume in $1 \mathrm{~s}\left(\mathrm{FEV}_{1}\right)$ and forced vital capacity (FVC) reflecting substantial agreement with international standards. ${ }^{6}$ The current literature also demonstrates clear modifiable, environmental risk factors for chronic respiratory disease, such as smoking and occupational exposures. $^{7}$

In childhood, genetic factors and developmental influences also appear to be relevant. Early life evidence suggests that the complex causal pathways to several non-communicable diseases occur in childhood through a variety of biopsychosocial factors. ${ }^{8}$ For example, Tai $e t$ $a l$ found that lung function in adult life is mainly determined in childhood, and that those with lower lung function in childhood were more likely to have asthma and COPD later in life. ${ }^{9}$ In addition, low $\mathrm{FEV}_{1}$ in early adulthood contributes significantly to the genesis of COPD in later years. ${ }^{10}$ Published studies provide consistent evidence for familial aggregation of spirometric indices, suggesting that around $20 \%-60 \%$ of total phenotypic variance may be explained by familial factors, ${ }^{11-16}$ but few studies have quantified intergenerational concordance at the population level. This could lead to new ways of predicting the population risk of non-communicable respiratory disease or even the possibility of targeted screening to individuals when a relative is identified with a heritable condition. ${ }^{17}$

The Child Health CheckPoint, nested within the Longitudinal Study of Australian Children (LSAC, also known as Growing Up in Australia), offered a comprehensive health assessment to participants. This included lung function testing of children aged 11-12 years and one of their parents using reliable, valid epidemiological measures, specifically $\mathrm{FEV}_{1}$, FVC and mid expiratory flow (MEF), on the same day and using the same equipment and protocols. Drawing on this population-based sample, the aims of this study were to (1) describe the epidemiology of lung function in Australian children aged 11-12 years and their parents and (2) investigate parent-child concordance in these same measures.

\section{METHODS}

\section{Study design and participants}

LSAC is Australia's only national longitudinal child study. Details of the LSAC study design and recruitment are provided elsewhere. ${ }^{18-20}$ Briefly, commenced in 2004 as the $\mathrm{B}$ and $\mathrm{K}$ cohorts, data collection has taken place every 2years. This included home visits and mailed questionnaires. The LSAC B cohort (reported in this paper) included 5107 families in the first wave, a $57.2 \%$ uptake of the 8921 families contacted. After 10 years of the study, 4484 of these families participated in wave 6 (2014). During this wave 6 home visit, B cohort families were introduced to the upcoming Child Health CheckPoint and asked to consent to their contact details being shared with the CheckPoint team. Those who consented (3513 families, $78 \%$ of wave 6 cohort and $69 \%$ of original cohort) received an information pack via mail, and an information and recruitment phone call during 2015.

Child Health CheckPoint data collection spanned February 2015 to March 2016, and 1874 families participated (figure 1). In seven major Australian cities, the study child and one of their parents were invited to participate in a 3.5-hour clinic assessment which included 17 different assessment stations. In eight regional towns, there were 2.75-hour mini assessment centres, which included the same assessments as those made in major cities except for those requiring large equipment that could not be checked in as personal luggage on commercial flights. Families unable to attend a clinic appointment were offered a 1.5-hour home visit with a subset of measures that could be conducted in the home by a researcher using portable equipment. A more detailed description of the CheckPoint study design is provided elsewhere. ${ }^{21} 22$

\section{Consent}

The attending parent provided written informed consent for themselves and their child to participate in the study.

\section{Patient and public involvement}

Because LSAC is a population-based longitudinal study, no patient groups were involved in its design or conduct. To our knowledge, the public was not involved in the study design, recruitment or conduct of the LSAC study or its CheckPoint module. Parents received a summary health report for their child and themselves at or soon 
after the assessment visit. Parents consented to take part knowing that they would not otherwise receive individual results about themselves or their child.

\section{Procedures}

Spirometry, height and weight were measured at an assessment centre or at a home visit. Participants were included in these analyses if they met American Thoracic Society (ATS) /European Respiratory Society (ERS) criteria for spirometry (see the Lung function measures section). Reasons for a lack of useable data included equipment failure, poor quality data or time constraints. Data from 20 non-biological child-parent pairs were excluded from concordance analyses.

\section{Lung function measures}

Participants completed spirometry testing with measures including $\mathrm{FEV}_{1}$, FVC and MEF. Prior to testing, spirometers were calibrated using a $3 \mathrm{~L}$ syringe with adjustments made for current ambient conditions. Spirometry was performed using a Vyntus Pneumo spirometer running SentrySuite software (Care Fusion, Germany) with a bacterial filter and nose clip in place. These data were converted to z-scores using the Global Lung Initiative (GLI) 2012 reference equations. ${ }^{23}$ Children also undertook postbronchodilator spirometry, which is not reported here.

Spirometry was performed in accordance with ATS/ ERS guidelines. ${ }^{5}$ First, the researcher explained and demonstrated the correct performance of spirometry to study participants. This included an emphasis on correct posture with the head slightly elevated, a tight seal around the mouthpiece with no leak, a rapid and complete inhalation to total lung capacity, followed by a rapid maximal exhalation until residual volume was reached while maintaining an upright posture. Adhering to these instructions, participants then performed a minimum of three and a maximum of eight spirometry trials. Via its DataCube function, data were exported from the SentrySuite platform into a Microsoft Excel spreadsheet. The quality of all flow-volumes loops were assessed by LW and SR. Data were assessed to determine if the loops met ATS/ERS criteria (see the ATS/ERS acceptability criteria section), if two acceptable manoeuvres were obtained, each participant's best loop was identified. FEV $_{1}$, FVC and MEF scores were derived from the best loop.

\section{ATS/ERS Acceptability Criteria}

\section{A. Start of test}

Assessed by visual inspection of the flow-volume trace. A rapid rise to and clearly defined peak expiratory flow.

B. Within manoeuvre

Assessed by visual inspection of the flow-volume trace.

Manoeuvre was free from artefact, cough within the first second, glottic closure or obvious leak.

C. End of test

Assessed by visual inspection of the volume-time trace.
Clear end-expiratory plateau on volume-time trace with no sharp drop or cessation of flow. There was no specification for a minimal forced expiratory time.

D. Repeatability

Two largest $\mathrm{FEV}_{1}$ and $\mathrm{FVC}$ values were within $150 \mathrm{~mL}$.

A quality score between 1 and 5 was assigned to each loop.

1. Meets all of the ATS/ERS criteria (met acceptability criteria for A, B, C and D).

2. Meets all ATS/ERS criteria except for repeatability. Two largest FVC values had a difference of $>150 \mathrm{~mL}$.

3. Meets all ATS/ERS criteria except for repeatability. Two largest $\mathrm{FEV}_{1}$ values had a difference $>150 \mathrm{~mL}$.

4. Does not meet ATS/ERS guidelines; data excluded from dataset.

5. Meets all ATS/ERS criteria except for repeatability. Two largest $\mathrm{FVC}$ and $\mathrm{FEV}_{1}$ values had a difference $>150$ $\mathrm{mL}$.

Loops that were assigned a quality control score of 1,2 , 3 or 5 were included in the dataset.

\section{Other sample characteristics}

Age and gender were obtained via the Medicare Australia database for children and were self-reported by parents. In Australia, socioeconomic indexes for areas provide standardised scores for socioeconomic status by geographic area (postcode of family domicile) compiled from 2011 Australian census data. We used the index of relative socioeconomic disadvantage (disadvantage index) which numerically summarises the social and economic status of Australian neighbourhoods (national mean of 1000 and an SD of 100, with a higher score indicating less disadvantage and a lower score indicating more disadvantage). ${ }^{24}$

Height and weight were recorded prior to spirometry measurement. Standing height was measured to the nearest $0.1 \mathrm{~cm}$ without shoes and socks, in duplicate, using a portable rigid stadiometer (Invicta IP0955, Leicester, UK). A third measurement was taken if the difference of the first two measurements exceeded $0.5 \mathrm{~cm}$; final height was the mean of all measurements made. Weight to the nearest $0.1 \mathrm{~kg}$ was measured wearing light clothing without shoes or socks using an InBody230 bioelectrical impedance analysis scale (Biospace Co., Seoul, South Korea) at assessment centres or with a 2-limb body composition scale (Tanita BC-351, USA) at home visits. Body mass index (BMI) was calculated as weight $(\mathrm{kg})$ divided by height $(\mathrm{m})$ squared. For children, an age-adjusted and sex-adjusted BMI z-score was calculated using the US Centers for Disease Control growth reference charts. ${ }^{25}$

A preclinic checklist including questions about a diagnosis of asthma and shortness of breath causing restriction was completed by parents and brought to the assessment.

\section{Statistical analysis}

Statistical analyses were performed using Stata V.14.2. Continuous descriptive variables were summarised using weighted means and $\mathrm{SD}$; categorical variables were summarised by number and weighted percentage for 
children and adults separately, by sex and overall. The approximate normality or otherwise of the data's distributions were assessed through visual inspection.

Population summary statistics and proportions were estimated by applying survey weights and survey procedures that corrected for the sampling frame, participation and non-response, and took into account clustering in the sampling frame. SEs were calculated taking into account the complex design and weights. ${ }^{26}$ More detail on the calculation of the survey weights is provided elsewhere. $^{27}$

Parent-child concordance was assessed by (1) Pearson's correlation coefficients with 95\% CIs and (2) linear regression with the child variable as the dependent variable and the parent variable as the independent variable adjusted for the potential confounders. The Pearson's correlation and linear regression analyses were repeated using weighted multilevel survey analyses; as these yielded similar results, unweighted results are presented.

An abnormal $\mathrm{FEV}_{1} / \mathrm{FVC}$ z-score was defined as any result $<-2.0$. Study data were collected and managed using Research Electronic Data Capture electronic data capture tools. $^{28}$

\section{RESULTS}

\section{Sample characteristics}

Figure 1 depicts participation in the Child Health CheckPoint study. One thousand seven hundred and fifty-nine children and 1774 parents successfully completed spirometry testing in line with ATS/ERS criteria, ${ }^{5}$ including 1668 biological parent-child dyads.

Sample characteristics are presented in table 1 . Among the child cohort, boys and girls were roughly equally represented $(51.2 \%$ boys), but most $(87.5 \%)$ parents were mothers. For children, the sample population had a somewhat higher mean BMI than the historical reference population, in keeping with the known current epidemiology of BMI for Australian children. For parents, mean BMI fell within the 'overweight' category according to the US Centers for Disease Control and Prevention. ${ }^{25}$ The mean disadvantage index was 1009 (62) which is marginally above the Australian national mean of 1000, but with a lower spread (SD 62 vs 100 nationally) such that very disadvantaged families were under-represented. ${ }^{29}$

Two hundred and forty-one children (13.7\%) and 179 parents $(10 \%)$ reported a diagnosis of asthma. Only 11 children and 24 parents reported shortness of breath causing restriction.

\begin{tabular}{|c|c|c|c|}
\hline Characteristic & All & Male & Female \\
\hline \multicolumn{4}{|l|}{ Child } \\
\hline Age, years & $12.0(0.4)$ & $12.0(0.4)$ & $12.0(0.4)$ \\
\hline Height, cm & $153.8(8.0)$ & $153.4(8.3)$ & $154.3(7.7)$ \\
\hline BMI, kg/m² & $19.5(3.7)$ & $19.3(3.6)$ & $19.7(3.7)$ \\
\hline BMI z-score & $0.37(1.03)$ & $0.36(1.07)$ & $0.39(1.00)$ \\
\hline Waist circumference, $\mathrm{cm}$ & $66.9(9.0)$ & $67.5(9.0)$ & $66.1(8.9)$ \\
\hline Disadvantage index & 1009 (62) & 1009 (62) & $1010(62)$ \\
\hline \multicolumn{4}{|l|}{ Parent } \\
\hline $\mathrm{n}$ & $1756-1774$ & $218-221$ & $1536-1553$ \\
\hline Age, years & $43.7(5.6)$ & $46.2(7.0)$ & $43.4(5.3)$ \\
\hline Height, cm & 165.9 (7.8) & $177.7(7.4)$ & $164.2(6.3)$ \\
\hline Weight, kg & $78.2(19.1)$ & $91.4(17.4)$ & $76.4(18.6)$ \\
\hline $\mathrm{BMI}, \mathrm{kg} / \mathrm{m}^{2}$ & $28.4(6.4)$ & $28.9(4.9)$ & $28.3(6.6)$ \\
\hline Waist circumference, $\mathrm{cm}$ & $87.9(15.1)$ & $98.1(13.4)$ & $86.4(14.8)$ \\
\hline Asthma reported (\%) & 9.9 & 3.6 & 10.8 \\
\hline Shortness of breath causing restriction (\%) & 1.8 & 2.2 & 1.8 \\
\hline
\end{tabular}

Disadvantage index, index of relative socioeconomic disadvantage; $n$, number of participants in cohort with this measure.

BMI, body mass index. 


\section{Population epidemiology of lung function}

The mean, SD and z-scores for $\mathrm{FEV}_{1}, \mathrm{FVC}, \mathrm{FEV}_{1} / \mathrm{FVC}$ and $\mathrm{MEF}$ are shown in table 2. All measures of lung function in children and adults followed approximately normal distributions; plots of distribution and density for $\mathrm{FEV}_{1}$, FVC, FEV $_{1} /$ FVC and MEF z-scores are shown in figures 2 and 3 for parents and children, respectively.

On average, boys and girls had $\mathrm{FEV}_{1}, \mathrm{FVC}$ and $\mathrm{MEF}$ z-scores that were within normal limits, as did parents. Lung function followed similar distributions in children and parents, with mean $\mathrm{FEV}_{1}$ z-scores of $\sim 0.3$ and FVC z-scores of $\sim 0.8$, reflecting higher values than the international reference populations. Conversely, $\mathrm{FEV}_{1} / \mathrm{FVC}$ and MEF z-scores, of approximately -0.8 and -0.5 , indicated lower values than the international reference populations (see table 2). The proportion of children with lung function z-score below the normal range (<-2 z-score) was $1.7 \%$ for $\mathrm{FEV}_{1} ; 0.6 \%$ for FVC; $12.9 \%$ for $\mathrm{FEV}_{1} / \mathrm{FVC}$ and $8.1 \%$ for MEF, respectively. This was similar in parents, where the proportion of lung function below the lower limit of normal was $2.7 \%$ for $\mathrm{FEV}_{1} ; 1.3 \%$ for $\mathrm{FVC} ; 13.7 \%$ for $\mathrm{FEV}_{1} / \mathrm{FVC}$ ratio and $7.9 \%$ for MEF, respectively.

\section{Parent-child concordance}

Two models of child-parent concordance are displayed in table 3. Pearson's correlations between children and parents for $\mathrm{FEV}_{1}, \mathrm{FVC}$ and $\mathrm{MEF} \mathrm{z}$-score all showed modest significant positive correlations. The strongest association was seen in $\mathrm{FEV}_{1} / \mathrm{FVC}$ z-score (correlation coefficient $0.25,95 \% \mathrm{CI} 0.20$ to 0.29 ). Associations strengthened marginally on conversion to z-scores and thereby adjusting for age, sex and height. The linear regression model also showed similar relationships between child and parent lung function indices, when adjusted for covariates (child and parental age, sex, BMI and parental smoking at wave 6), irrespective of the parent being a mother or a father.

When using a $\mathrm{FEV}_{1} / \mathrm{FVC}$ ratio z-score of $<-2.0$ to define abnormality we found the following: parent and child both normal, 1282 (77.6\%); parent abnormal but child normal, 163 (9.9\%); parent normal but child abnormal, 159 (9.6\%); both abnormal $49(3.0 \%)$.

\section{DISCUSSION}

\section{Principal findings}

This study represents the largest report of spirometry in children aged 11-12 years across Australia. Lung function parameters were on average within normal limits for parents and children, with mean above the international predicted mean for $\mathrm{FEV}_{1}$ and $\mathrm{FVC}$ while being below the predicted mean for $\mathrm{FEV}_{1} / \mathrm{FVC}$. With regard to concordance, there were modest positive correlations between child and parent lung function indices of around 0.200.25 including $\mathrm{FEV}_{1}$, FVC and MEF. Importantly, the strongest concordance between children and parents was for the $\mathrm{FEV}_{1} / \mathrm{FVC}$ z-score, which represents the relationship between airway size and lung volume and is the most sensitive spirometric index for detecting airway obstruction.

\section{Strengths and limitations}

Within this large child cohort there was equal representation from boys $(51.2 \%)$ and girls, but mothers were over-represented $(87.5 \%)$. Nonetheless, the 221 fathers showed very similar patterns in the four parameters and their z-scores to mothers and to the children, although with some loss of precision in their estimates. Despite this, we recognise that we probably do not have a random selection of mothers and fathers, and suggest that our results should therefore be interpreted with the acknowledgement that the father sample could be biased. Importantly, a large proportion of mothers could also be viewed as a strength of our study given the influence of maternal factors and in utero environment on the future development of non-communicable disease ${ }^{30}$ We acknowledge that this was a cross-sectional study but highlight that our analyses have been adjusted for current parental smoking. Although smoking rates in Australia have declined significantly and are currently at their lowest levels in history, ${ }^{30}$ it is well established that exposure to smoking can have a life-long impact on peak lung function. ${ }^{31}$

\section{Interpretation in light of current literature}

Compared with previous population studies of lung function, we showed somewhat larger mean absolute volumes for $\mathrm{FEV}_{1}$ and FVC in children and adults of similar age and height. ${ }^{32}$ Hall et al defined the minimum physiologically relevant difference to be $0.5 \mathrm{z}$-scores, equating to a difference of $\sim 6 \%$ predicted in their study of contemporary Australasian individuals. Mean (SD) z-scores for their data were 0.23 (1.00) for $\mathrm{FEV}_{1}, 0.23$ (1.00) for FVC, -0.03 (0.87) for $\mathrm{FEV}_{1} / \mathrm{FVC}$ and 0.07 (0.95) for $\mathrm{FEF}_{25-75}$, all of which were considered well within the range considered to be physiologically irrelevant. ${ }^{6}$ When adjusted for age, sex and height using the GLI prediction models, ${ }^{23}$ mean $\mathrm{FEV}_{1}$, FVC and MEF z-scores were all within normal limits for children and their parents but above the GLI predicted mean, with patterns similar to but more marked than identified by Hall et al. This suggests that on average children, and their parents, in Australia have better lung volumes than the GLI reference population. This could be associated with the lower prevalence of smoking in Australia or that those with significant disadvantage, who might have lower lung function, were relatively under-represented in this study.

The $\mathrm{FEV}_{1} / \mathrm{FVC}$ ratio was below normal in $\sim 13 \%$ of either children or their parents. This ratio reflects airway size relative to lung volume and might be explained by the concept of dysanaptic growth where the airways and lung parenchyma grow disproportionately. This is thought to be influenced by gender-specific pubertal status. A low ratio can indicate airway obstruction. Differences in technique and equipment may also have contributed. For example, suboptimal effort during the initial part of a forced expiratory manoeuvre, where flows remain partly effort-dependent, could underestimate $\mathrm{FEV}_{1}$ but FVC would be preserved if the expiration proceeded to residual volume (akin to a slow vital capacity manoeuvre). Even though all 


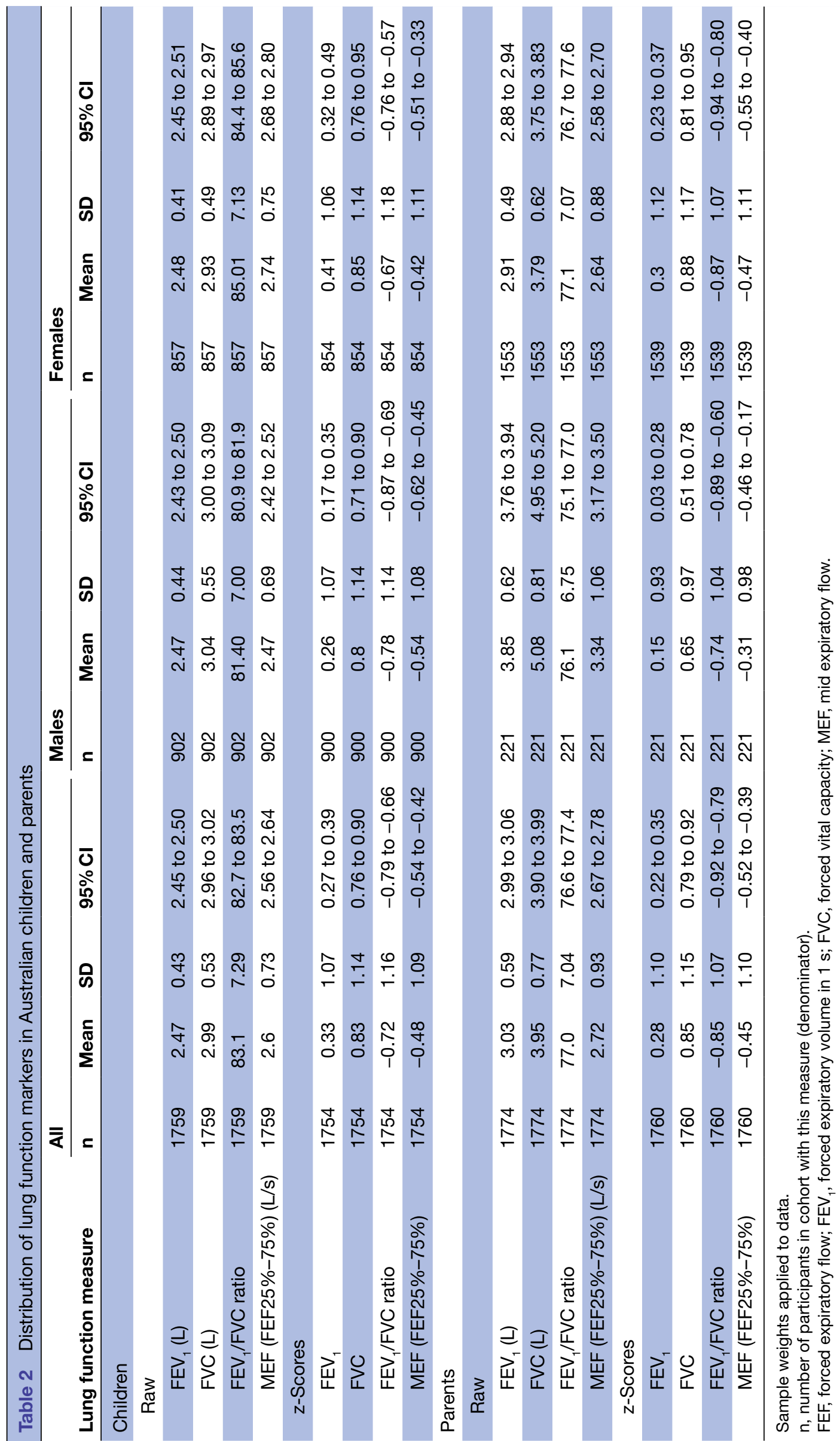



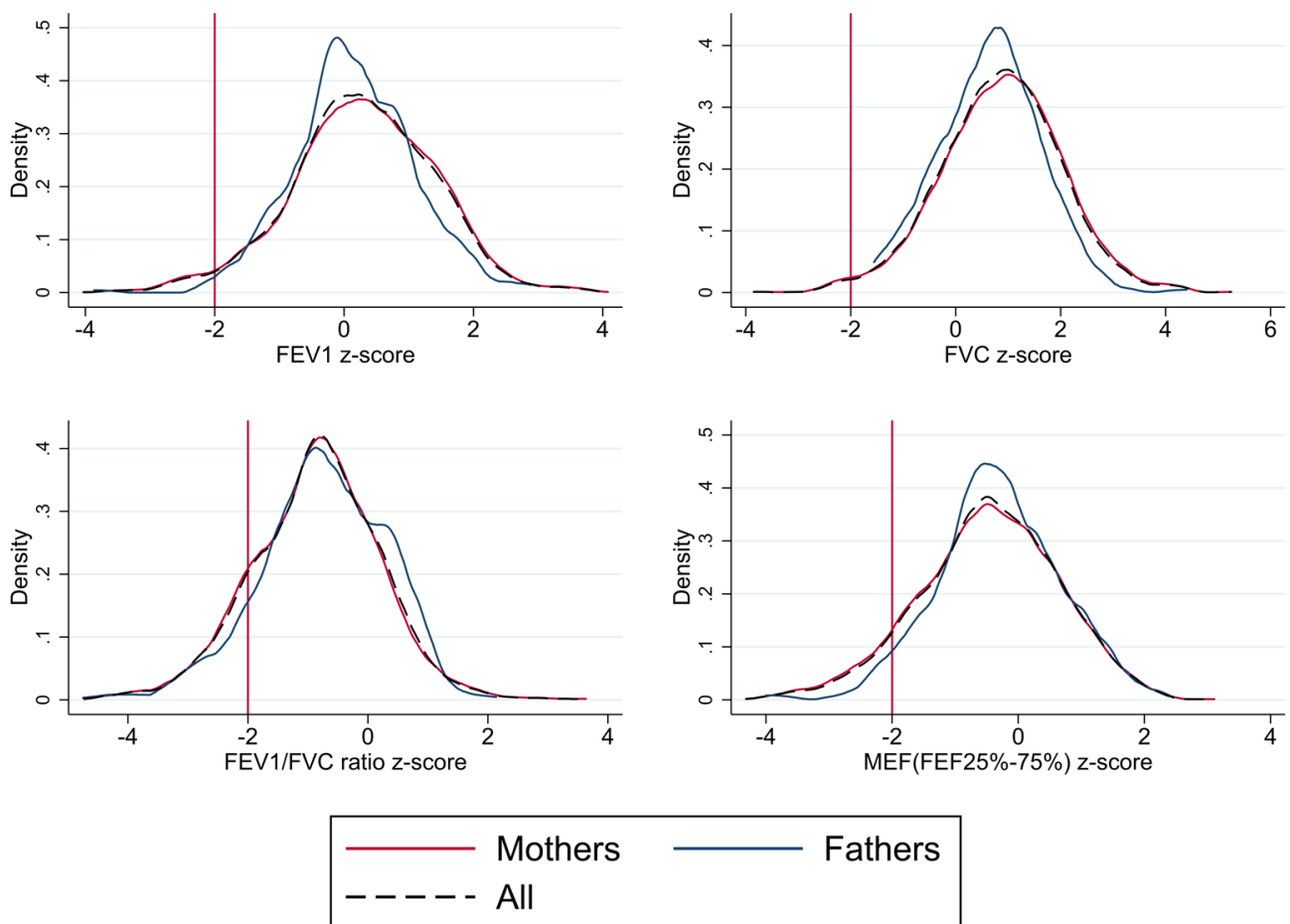

Figure 2 Lung function distribution and density plots for parents. FEF, forced expiratory flow; $\mathrm{FEV}_{1}$, forced expiratory volume in $1 \mathrm{~s}$; FVC, forced vital capacity; MEF, mid expiratory flow.

flow-volume loops were inspected, it is possible that subtle suboptimal efforts could have gone undetected, thereby underestimating $\mathrm{FEV}_{1}$. However, the similarities with the findings of those reported by Hall et al suggest that our findings are replicable. Additionally, FVC increases with sitting height, and a lower $\mathrm{FEV}_{1} / \mathrm{FVC}$ ratio might occur
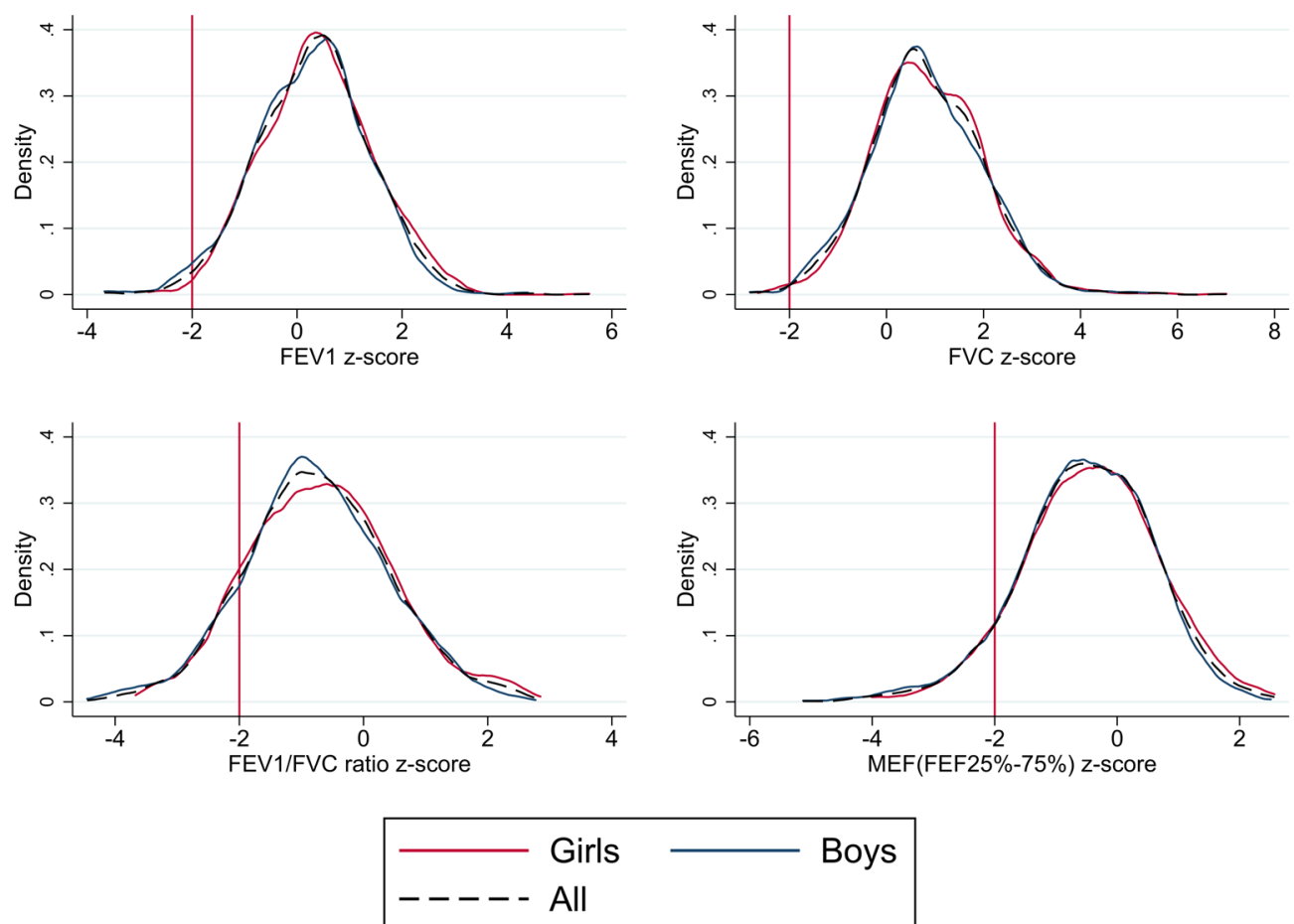

Figure 3 Lung function distribution and density plots for children. FEF, forced expiratory flow; $\mathrm{FEV}_{1}$, forced expiratory volume in $1 \mathrm{~s}$; FVC, forced vital capacity; MEF, mid expiratory flow. 
Table 3 Parent-child concordance

\begin{tabular}{|c|c|c|c|c|c|c|c|c|c|}
\hline \multirow[b]{2}{*}{ Pearson's correlation } & \multicolumn{3}{|c|}{ Parent-child } & \multicolumn{3}{|c|}{ Mother-child } & \multicolumn{3}{|c|}{ Father-child } \\
\hline & $\mathrm{N}$ & $\mathrm{CC}$ & $95 \% \mathrm{Cl}$ & $\mathrm{N}$ & $\mathrm{CC}$ & $95 \% \mathrm{Cl}$ & $\mathrm{N}$ & $\mathrm{CC}$ & $95 \% \mathrm{Cl}$ \\
\hline \multicolumn{10}{|l|}{ Raw } \\
\hline $\mathrm{FEV}_{1}$ & 1668 & 0.19 & 0.15 to 0.24 & 1454 & 0.20 & 0.15 to 0.25 & 214 & 0.21 & 0.07 to 0.33 \\
\hline FVC & 1668 & 0.21 & 0.17 to 0.26 & 1454 & 0.24 & 0.19 to 0.29 & 214 & 0.20 & 0.07 to 0.33 \\
\hline $\mathrm{FEV}_{1} / \mathrm{FVC}$ ratio & 1668 & 0.23 & 0.18 to 0.27 & 1454 & 0.24 & 0.19 to 0.29 & 214 & 0.17 & 0.04 to 0.30 \\
\hline MEF (FEF25\%-75\%) & 1668 & 0.20 & 0.15 to 0.24 & 1454 & 0.21 & 0.16 to 0.26 & 214 & 0.15 & 0.02 to 0.28 \\
\hline \multicolumn{10}{|l|}{ z-Score } \\
\hline $\mathrm{FEV}_{1}$ & 1653 & 0.22 & 0.17 to 0.26 & 1439 & 0.22 & 0.17 to 0.27 & 214 & 0.25 & 0.12 to 0.38 \\
\hline FVC & 1653 & 0.24 & 0.20 to 0.29 & 1439 & 0.25 & 0.20 to 0.29 & 214 & 0.22 & 0.09 to 0.35 \\
\hline $\mathrm{FEV}_{1} / \mathrm{FVC}$ ratio & 1653 & 0.25 & 0.20 to 0.29 & 1439 & 0.26 & 0.21 to 0.30 & 214 & 0.21 & 0.08 to 0.34 \\
\hline MEF & 1653 & 0.24 & 0.20 to 0.29 & 1439 & 0.24 & 0.19 to 0.29 & 214 & 0.26 & 0.13 to 0.38 \\
\hline Adjusted linear regression & $\mathrm{N}$ & $\mathrm{RC}$ & $P$ value & $\mathrm{N}$ & $\mathrm{RC}$ & $P$ value & $\mathrm{N}$ & $\mathrm{RC}$ & $P$ value \\
\hline \multicolumn{10}{|l|}{ Raw } \\
\hline $\mathrm{FEV}_{1}$ & 1610 & 0.16 & $<0.001$ & 1435 & 0.16 & $<0.001$ & 175 & 0.19 & $<0.001$ \\
\hline FVC & 1610 & 0.17 & $<0.001$ & 1435 & 0.17 & $<0.001$ & 175 & 0.15 & 0.001 \\
\hline $\mathrm{FEV}_{1} / \mathrm{FVC}$ ratio & 1610 & 0.26 & $<0.001$ & 1435 & 0.26 & $<0.001$ & 175 & 0.21 & 0.004 \\
\hline MEF (FEF25\%-75\%) & 1610 & 0.19 & $<0.001$ & 1435 & 0.20 & $<0.001$ & 175 & 0.17 & $<0.001$ \\
\hline \multicolumn{10}{|l|}{ z-Score } \\
\hline $\mathrm{FEV}_{1}$ & 1598 & 0.21 & $<0.001$ & 1423 & 0.21 & $<0.001$ & 175 & 0.29 & $<0.001$ \\
\hline FVC & 1598 & 0.24 & $<0.001$ & 1423 & 0.25 & $<0.001$ & 175 & 0.30 & 0.001 \\
\hline $\mathrm{FEV}_{1} / \mathrm{FVC}$ ratio & 1598 & 0.28 & $<0.001$ & 1423 & 0.29 & $<0.001$ & 175 & 0.24 & 0.002 \\
\hline MEF & 1598 & 0.25 & $<0.001$ & 1423 & 0.25 & $<0.001$ & 175 & 0.30 & $<0.001$ \\
\hline
\end{tabular}

Covariates models include child and parental age, sex BMI and current parental smoking.

$\mathrm{N}$, number of biological child-parent pairs with this measure.

CC, Pearson's correlation coefficients; FEF, forced expiratory flow; FEV 1 , forced expiratory volume in $1 \mathrm{~s}$; FVC, forced vital capacity; MEF, mid expiratory flow; RC, estimated regression coefficient.

if our population was of greater sitting height than the reference population but we were not able to adjust for this as sitting height was not measured. ${ }^{33}$ Matched FEV $/$ FVC ratio below the normal range occurred in only $3 \%$ of child-parent dyads.

All measurements were reported from prebronchodilator flow-volume loops as was reported in the lung function reference populations. We successfully measured response to bronchodilator (following $400 \mu \mathrm{g}$ salbutamol) in 179 children with $\mathrm{FEV}_{1} / \mathrm{FVC}$ ratio $<-2$ z-scores (data not shown). Fifty-three (30\%) had evidence of a significant response to bronchodilator (defined as $\geq 12 \%$ and $\geq 200 \mathrm{~mL}$ improvement in absolute $\mathrm{FEV}_{1}$ ), suggesting that many children with this ratio below the normal range have reversible airways obstruction. This is usually considered a characteristic feature of asthma.

Our intergenerational concordance findings for lung function extend the small published literature on the heritability and familial aggregation of lung function. ${ }^{143435}$ In the oldest published study dating back to 1984, Lebowitz et al did not find any relationship between parents' and children's lung function after accounting for body habitus. ${ }^{14}$ However, our child-one parent dyadic concordance values of around $0.20-0.25$ are very consistent with the Busselton Health Study in Western Australia, ${ }^{34}$ whose narrow-sense heritability (which takes into account contributions from both parents) for $\mathrm{FEV}_{1}$ and FVC were $38.9 \%$ and $40.6 \%$. In contrast to the Busselton study where assessments were made at an offspring age of 45 years, we identified this concordance when children were between 11 and 12 years of age, prior to the likely influence of cigarette smoking and genetic susceptibility to lung injury on heritability. Xu et al identified significant correlations in parent child lung function in both families of children with asthma and healthy, non-asthmatic children. In healthy children, this correlation was similar for maternal (0.22) and paternal first child (0.24) $\mathrm{FEV}_{1}$, both again being remarkably similar to those identified in the current study. These data indicate that heritability of lung function requires further exploration when considering long-term outcomes of early lung function. ${ }^{35}$

Meaning and interpretation for clinicians and policymakers Taken together, these results show lung volumes above predicted population means for Australian children aged 11-12 years and positive intergenerational concordance 
between their lung function and those of their parents. Though modest, the associations highlight the potential for better identification of 'at risk' patients while also indicating that there are likely to be many other factors at play. If parents manifest low lung function then it is possible that targeting their offspring for screening and potential intervention might serve to prevent low lung function or lung function decline in the child.

\section{Conclusions and future directions}

Lung function indicating lower airway size relative to lung volume in this population may be due to multiple factors but warrants further assessment over time for evidence of airway obstruction. Our findings indicate the need to explore factors relating to intergenerational concordance in lung function further in order to develop health policy that aims to prevent the onset or limit the progression of lung disease.

Acknowledgements This paper uses unit record data from Growing Up in Australia, the Longitudinal Study of Australian Children. The study is conducted in partnership between the Department of Social Services (DSS), the Australian Institute of Family Studies (AIFS) and the Australian Bureau of Statistics (ABS). Some study data were collected and managed using Research Electronic Data Capture (REDCap) electronic data capture tools. REDCap is a secure, web-based application designed to support data capture for research studies. More information about this software can be found at: www.project-redcap.org. The authors thank the LSAC and CheckPoint study participants, staff and students for their contributions.

Contributors LW, GK and TR contributed to the interpretation of results, drafted the initial manuscript, critically revised further drafts and approved the final manuscript as submitted. ACG performed the statistical analyses, contributed interpretation of results and critical review of the manuscript. SR contributed to the interpretation of results and provided critical review of the manuscript. MW is the principal investigator of the Child Health CheckPoint, planned the analyses and provided critical review of the manuscript.

Funding This work was supported by the National Health and Medical Research Council (NHMRC) of Australia (Project Grants 1041352, 1109355), The Royal Children's Hospital Foundation (2014-241), the Murdoch Children's Research Institute (MCRI), The University of Melbourne, the Financial Markets Foundation for Children (2014-055, 2016-310) and the National Centre for Longitudinal Data (NCLD). MW was supported by an NHMRC Senior Research Fellowship (1046518). The MCRI administered the research grants for the study and provided infrastructural support (IT and biospecimen management) to its staff and the study, but played no role in the conduct or analysis of the trial. DSS played a role in study design; however, no other funding bodies had a role in the study design and conduct; data collection, management, analysis and interpretation; preparation, review or approval of the manuscript; and decision to submit the manuscript for publication. Research at the MCRI is supported by the Victorian Government's Operational Infrastructure Support Program.

Disclaimer The findings and views reported in this paper are those of the author and should not be attributed to DSS, AIFS or the ABS.

Competing interests All authors have completed the ICMJE uniform disclosure form at www.icmje.org/coi_disclosure.pdf and declares financial support as described in the funding section. MW received support from Sandoz to present at a symposium outside the submitted work.

Patient consent for publication Not required.

Ethics approval The study protocol was approved by The Royal Children's Hospital Melbourne Human Research Ethics Committee (33225D) and Australian Institute of Family Studies Ethics Committee (14-26)

Provenance and peer review Not commissioned; externally peer reviewed.

Data sharing statement The Longitudinal Study of Australian Children datasets and technical documents are available to researchers at no cost via a licence agreement. Data access requests are co-ordinated by the National Centre for
Longitudinal Data. More information is available at https://dataverse.ada.edu.au/ dataverse/lsac.

Open access This is an open access article distributed in accordance with the Creative Commons Attribution Non Commercial (CC BY-NC 4.0) license, which permits others to distribute, remix, adapt, build upon this work non-commercially, and license their derivative works on different terms, provided the original work is properly cited, appropriate credit is given, any changes made indicated, and the use is non-commercial. See: http://creativecommons.org/licenses/by-nc/4.0/.

\section{REFERENCES}

1. Ferkol T, Schraufnagel D. The global burden of respiratory disease. Ann Am Thorac Soc 2014;11:404-6.

2. Lopez AD, Shibuya K, Rao C, et al. Chronic obstructive pulmonary disease: current burden and future projections. Eur Respir $J$ 2006;27:397-412.

3. Alwan A, Armstrong T, Bettcher D, et al. Global status report on noncommunicable diseases 2010. In: Organization WH, ed 2011.

4. Treasury. 2015 intergenerational report. Australia in 2055. Canberra: Commonwealth of Australia, 2015.

5. Miller MR, Hankinson J, Brusasco V, et al. Standardisation of spirometry. Eur Respir J 2005;26:319-38.

6. Hall GL, Thompson BR, Stanojevic S, et al. The Global Lung Initiative 2012 reference values reflect contemporary Australasian spirometry. Respirology 2012;17:1150-1.

7. Murray CJ, Lopez AD. Global mortality, disability, and the contribution of risk factors: Global Burden of Disease Study. Lancet 1997;349:1436-42.

8. Renz $\mathrm{H}$, von Mutius E, Brandtzaeg P, et al. Gene-environment interactions in chronic inflammatory disease. Nat Immunol 2011;12:273-7.

9. Tai $A$, Tran $H$, Roberts $M$, et al. The association between childhood asthma and adult chronic obstructive pulmonary disease. Thorax 2014;69:805-10.

10. Lange $P$, Celli $B$, Agustí $A$, et al. Lung-function trajectories leading to chronic obstructive pulmonary disease. $N$ Engl J Med 2015;373:111-22.

11. Chen Y, Horne SL, Rennie DC, et al. Segregation analysis of two lung function indices in a random sample of young families: the Humboldt Family Study. Genet Epidemiol 1996;13:35-47.

12. Cotch MF, Beaty TH, Cohen BH. Path analysis of familial resemblance of pulmonary function and cigarette smoking. Am Rev Respir Dis 1990;142(6 Pt 1):1337-43.

13. Higgins M, Keller J. Familial occurrence of chronic respiratory disease and familial resemblance in ventilatory capacity. J Chronic Dis 1975;28:239-51.

14. Lebowitz MD, Knudson RJ, Burrows B. Family aggregation of pulmonary function measurements. Am Rev Respir Dis 1984;129:8-11.

15. Rybicki BA, Beaty $\mathrm{TH}$, Cohen $\mathrm{BH}$. Major genetic mechanisms in pulmonary function. J Clin Epidemiol 1990;43:667-75.

16. Tager IB, Rosner B, Tishler PV, et al. Household aggregation of pulmonary function and chronic bronchitis. Am Rev Respir Dis 1976;114:485-92.

17. Krawczak M, Cooper DN, Schmidtke J. Estimating the efficacy and efficiency of cascade genetic screening. Am J Hum Genet 2001;69:361-70.

18. Edwards B. Growing Up in Australia: the Longitudinal Study of Australian Children. Entering adolescence and becoming a young adult. Family Matters 2014;95:5-14.

19. Sanson A, Johnstone R. Growing Up in Australia takes its first steps. Family Matters 2004;67:46-53.

20. Soloff C, Lawrence D, Johnstone R. The Longitudinal Study of Australian Children: an Australian Government Initiative. LSAC Technical Paper No. 1. Australian Institute of Family Studies 2005.

21. Clifford S, Davies S, Wake M. Child Health Check Point Team. Child Health CheckPoint: Cohort summary and methodology of a physical health and biospecimen module for the Longitudinal Study of Australian Children. BMJ Open 2019;9(suppl 3):3-22.

22. Wake M, Clifford SA, York E. Introducing Growing Up in Australia's Child Health Check Point. Family Matters 2014;95:15-23.

23. Quanjer $\mathrm{PH}$, Stanojevic S, Cole TJ, et al. Multi-ethnic reference values for spirometry for the 3-95-yr age range: the global lung function 2012 equations. Eur Respir J 2012;40:1324-43.

24. Australian Bureau of Statistics. Secondary Census of Population and Housing: Socio- Economic Indexes for Areas (SEIFA) (cat. no. 2033.0.55.001). 2011 http://www.abs.gov.au/websitedbs/ censushome.nsf/home/seifa2011 
25. Kuczmarski RJ, Ogden CL, Grummer-Strawn LM, et al. CDC growth charts: United States. Adv Data 2000:1-27.

26. Heeringa SG, West BT, Berglund PA. Applied survey data analysis. Boca Raton, FL: CRC Press, 2010.

27. Ellul S, Hiscock R, Mensah FK, et al. Longitudinal Study of Australian Children's Child Health Check Point Technical Paper 1: Weighting and Non-Response. Melbourne: Murdoch Childrens Research Institute, 2018.

28. Harris PA, Taylor R, Thielke $\mathrm{R}$, et al. Research electronic data capture (REDCap)--a metadata-driven methodology and workflow process for providing translational research informatics support. J Biomed Inform 2009;42:377-81.

29. Pink B. Socio-Economic Indexes for Areas (SEIFA) - technical paper. Canberra: Australian Bureau of Statistics, 2011.

30. Vuillermin P, Saffery R, Allen KJ, et al. Cohort profile: the Barwon Infant Study. Int J Epidemiol 2015;44:1148-60.
31. Perret JL, Walters $\mathrm{H}$, Johns $\mathrm{D}$, et al. Mother's smoking and complex lung function of offspring in middle age: A cohort study from childhood. Respirology 2016;21:911-9.

32. Hibbert ME, Lannigan A, Landau LI, et al. Lung function values from a longitudinal study of healthy children and adolescents. Pediatr Pulmonol 1989;7:101-9.

33. Quanjer PH, Stanojevic S, Stocks J, et al. Changes in the FEV $/$ FVC ratio during childhood and adolescence: an intercontinental study. Eur Respir J 2010;36:1391-9.

34. Palmer LJ, Knuiman MW, Divitini ML, et al. Familial aggregation and heritability of adult lung function: results from the Busselton Health Study. Eur Respir J 2001;17:696-702.

35. Xu X, Yang J, Chen $\mathrm{C}$, et al. Familial aggregation of pulmonary function in a rural Chinese community. Am J Respir Crit Care Med 1999;160:1928-33. 